\title{
Los nombres de la realidad. Autoficción en Formas de volver a casa*
}

Fecha de recepción: 27 de marzo de 2017

Fecha de aprobación: 30 de junio de 2017

\section{Resumen}

Este trabajo tiene como centro de interés el estudio de la obra Formas de volver a casa (2011), del escritor chileno Alejandro Zambra. Se presta especial atención al análisis y descripción de los procedimientos autoficcionales de los que se sirve. La lectura de la novela permitirá atender a temas como la memoria, el pasado, los recuerdos de infancia, la exposición del autor a través de una ficción, así como los juegos onomásticos que determinan las relaciones de los personajes y del autor. A lo anterior, se añade la reflexión sobre los hechos que determinan el marco temporal de la obra: dos terremotos en Chile (1985 y 2010) y el período de la dictadura de Augusto Pinochet.

Palabras clave: autoficción, Alejandro Zambra, memoria, identidad, narrativa chilena.

Citar: Saavedra Galindo, A. (enero-junio de 2017). Los nombres de la realidad. Autoficción en Formas de volver a casa. La Palabra, (30), 93 - 106. doi: https://doi. org/10.19053/01218530.n30.2017.6213

\begin{abstract}
Alexandra Saavedra Galindo
DoctoraenLetras Latinoamericanas por la Universidad Nacional Autónoma de México. Becaria del Consejo Nacional de Ciencia y Tecnología (CONACyT) maestría y doctorado. Docente de la Universidad Nacional Autónoma de México.

alesaavedragalindo@gmail.com

* Este trabajo hace parte de la investigación posdoctoral «Ruptura genérica en la literatura latinoamericana contemporánea (siglo XXI)», que se realiza con el apoyo del Programa de Becas Posdoctorales de la UNAM, en el Centro de Investigaciones sobre América Latina y el Caribe.
\end{abstract}




\section{la palabra}

\section{The names of reality. Autofiction in Formas de volver a casa [Ways of Going Home]}

\section{Abstract}

This work focuses on the study of the novel Formas de volver a casa [Ways of going home] (2011), by the Chilean writer Alejandro Zambra, with particular attention to the analysis and description of the auto-fictional procedures used. The reading of the novel attends to subjects such as memory, the past, childhood remembrances, the author's self-exposure through fictional procedures, as well as to the name games and puzzles that determine the relationships between different characters and the author. The facts that determine the time frame of the work -two earthquakes in Chile (1985 and 2010) and the period of Augusto Pinochet's dictatorship- are also considered.

Keywords: Autofiction, Alejandro Zambra, Memory, Identity, Chilean narrative.

\section{Les noms du réel. Autofiction dans Formas de volver a casa [Formes de retour chez} soi]

\section{Résumé}

Dans ce travail nous étudierons les procédures d'autofiction dans l'oeuvre Formas de volver a casa (2011) de l'écrivain chilien Alejandro Zambra. Nous analyserons des sujets tels que la mémoire, le passé, les souvenirs d'enfance, l'exposition de l'auteur dans une fiction ainsi que les jeux onomastiques qui déterminent les rapports des personnages et de l'auteur. Nous réfléchirons sur les faits historiques qui construisent la temporalité de l'oeuvre: deux tremblements de terre au Chili (1985 et 2010) et la dictatures d' Auguste Pinochet.

Mots-clés: Autofiction, Alejandro Zambra, Mémoire, Identité, romans chiliens. 


\section{Leer es cubrirse la cara. Y escribir es mostrarla.}

--Alejandro Zambra

\section{Leer la autoficción}

Formas de volver a casa, publicada en 2011, la tercera novela del escritor chileno Alejandro Zambra, es una obra cuyo tema de interés dominante es la memoria, su constitución, la forma en que los recuerdos se organizan de manera orgánica como memoria. Volver a casa no es solo regresar, volver al punto del que se partió, al punto de origen; expresa también un sentido de la conformidad en el regreso, una aceptación tácita de los valores de casa. En cierto sentido, la obra se ocupa de la tensión, vale decir, de la dialéctica, entre lo disperso y único, entre los recuerdos concretos y el tapiz en el que se disponen estos en un todo continuo, en un todo con límites y sentido. Un paño en el que puede señalarse la función y el sentido de la trama, por una parte; y las formas y colores del dibujo, por otra. El recuerdo particular es el material de construcción, el ladrillo. La memoria pretende erigir un edificio con ese material. La memoria reconstruye lo que en su momento no fue construcción, pero lo es en el presente en el que la agencia histórica acopia materiales que ya estuvieron allí. El material, ciertamente, está o estaba ahí, pero disperso, aislado, y sin relación entre los diferentes elementos, como las piezas de una construcción o las de un rompecabezas.

Un narrador, del que no llega a saberse el nombre a lo largo de todo el relato, intenta entender sus lejanos recuerdos de infancia ligados al terremoto ocurrido en Santiago de Chile en 1985, y para ello, se analiza con minucioso detalle la vida de las personas con las que se relacionó en aquella época, así como el silencio, los secretos y el papel de los padres frente a la dictadura de Augusto Pinochet. Aparentemente, la novela sirve como medio para cuestionar las versiones oficiales de la dictadura y para reflexionar sobre la actuación de la sociedad durante los años de infancia del narrador. Es oportuno, pues, que el narrador no se identifique de forma inequívoca con un nombre, como así ocurre en esta obra. La ausencia del nombre alude a la intercambiabilidad de las experiencias. Es paradójico, sin duda, que una obra autoficcional juegue con los límites de lo imputable efectivamente al autor y lo que nace nuevo mediante los recursos amplios de la ficción. Pero, una obra autoficcional en la que el nombre del protagonista se deja en blanco, invita al lector a compartir -en primera persona- esas experiencias, las reales tanto como las imagina- rias; lo invita a que ponga su propio nombre a ese narrador, pero, si eso fuera imposible, lo invita también a que considere cuántas de las personas cercanas o lejanas, que vivieron los hechos narrados, podrían compartir esas experiencias. En ambos casos, las experiencias de la colectividad se superponen a los hechos narrados o son su segundo plano. Toda narración en primera persona es confesional, en gran medida. Toda narración en primera persona que suprime el nombre del narrador, se ofrece como un ejemplo que añade un valor de generalización a lo individual.

La obra está conformada por cuatro capítulos: «Personajes secundarios», «La literatura de los padres», «La literatura de los hijos»y «Estamos bien». Sin embargo, la estructura del texto se revela mucho más compleja, dado que los capítulos 2 y 4 , se dejan leer como el diario de un escritor, mientras que el 1 y 3 parecerían ser la materia de la propia novela sobre la que se reflexiona y sobre la que dice estar trabajando el prosista de los otros dos apartados. En ese orden de ideas, la novela es, al mismo tiempo, novela y diario. Pero no como suma, sino como relación dialéctica, pues la novela modifica al diario, y el diario condiciona la novela. 
Pero esta descripción no es inmediatamente visible para el lector, no se le entrega a este, como una estrategia de lectura, en las primeras páginas, porque, hasta bien avanzado el texto, no se define este, explícitamente, como diario, y esto ocurre cuando la voz del narrador afirma: «Semanas sin escribir en este diario. El verano entero» (Zambra, 2011, p. 162). Esta declaración puede leerse cuando tan solo faltan dos páginas para que concluya el relato. A lo largo de este, puede identificarse una serie de detalles que ponen en duda el género en el que podría inscribirse lo leído. No obstante, la delimitación y clasificación de la obra bajo las restricciones de un género narrativo específico y en el que los elementos biográficos adquieren una especial relevancia, permite a los lectores comprender -de otra manera- una serie de características y prácticas de tipo autoficcional en las que resulta oportuno detenerse. Si bien Formas de volver a casa no es un relato cuyo autor, narrador y protagonista comparten explícitamente una identidad nominal, característica que subvierte uno de los criterios determinantes para hablar de ella como autoficción, el texto de Zambra presenta una serie de datos $\mathrm{y}$ referencias que permiten este tipo de lectura.
Es importante recordar que la autoficción nació como un género híbrido ${ }^{1}$ mediante el que se materializaba la posibilidad de que autor, narrador y personaje compartieran el mismo nombre en un texto de índole explícitamente narrativa y que se presentaba como ficción. Pero, no menos importante, también mostraba que esa coincidencia nominal no resultaba incompatible con el «pacto de ficción». Conviene en este punto recordar algunas de las ideas que fundan este tipo de análisis. Son relevantes para entender la obra de Zambra. La propuesta de Doubrovsky llenaba el vacío que, unos años antes, Philippe Lejeune había advertido cuando, en su trabajo «Le pacte autobiographique», estudió los límites y las posibles lecturas de los textos autobiográficos. Lejeune se había enfrentado con el mismo tipo de problemas al tratar de aclarar que el «pacto referencial» y la comprobación de la información de los textos autobiográficos no eran suficientes para leer y entender una obra autobiográfica, dado que los autores siempre contaban su propia versión de la historia y, a su vez, esta solo contenía su verdad. Versión y verdad eran términos supuestamente excluyentes entre sí que exigían comprobaciones de naturaleza extratextual. Los autores ficcionalizaban su propia historia personal, biográfica y, al hacerlo, se alejaban de la frontera del campo biográfico, para aproximarse un poco más a la de la novela. Pero no por ello podían leerse las autobiografías como novelas ni, en sentido contrario, podían leerse las novelas como autobiografías.

La doble implicación, la implicación mutua, cancelaba simultáneamente los elementos ficcionales, que se leían necesariamente como autobiográficos, y los elementos autobiográficos, sobre los que caía la sombra de la sospecha de su ficcionalización. La cancelación mutua puede entenderse, asimismo, como una interpretación que ordena un régimen de posibilidades diferente. Se percibe a través de la autoficción, cómo la ficción interviene incluso en las mejor documentadas y fidedignas fotografías de la realidad; y cómo la realidad invade y ordena, de forma diferente, el terreno de la imaginación.

Recuérdese que Alberca (2007) propone una tipología de los relatos autoficcionales en los que la distancia o proximidad que el lector establece con el pacto de lectura autobiográfico, promueve una incertidumbre de interpretación sobre los elementos biográficos que se encuentren al interior del texto. Según el crítico español, las autoficciones

La clasificación de la autoficción como género se ha tomado del trabajo de Ana Casas (2012b), «El simulacro del yo: La autoficción en la narrativa actual» (ap. 9). Sin embargo, en este trabajo, la autoficción se entenderá como una práctica, sin entrar en consideraciones sobre si la autoficción debe o no clasificarse como un género. 
pueden ser clasificadas como autoficciones biográficas, autobioficción o autoficción fantástica (pp. 182 - 204), dentro de las que pueden presentarse diferentes modos de identidad nominal. Es decir, que la coincidencia entre el nombre del autor, narrador y personaje, sobre la que constantemente se hace énfasis, cuenta con algunas excepciones; y no en todos los casos, la identificación de los tres se lleva a cabo por medio, por ejemplo, de un mismo nombre, apellido o apodo.

Aunque Alberca (2007), antes de describir los modos de identidad nominal, aclara que:

[...] el nombre propio es la única forma de percibir el desafío que plantean las autoficciones. Dicho de otro modo, sin una referencia, el doble sentido de estas novelas no podría ser percibido ni expresado en su paradójica contradicción. Algunas interpretaciones que tienden a considerar como autoficción cualquier tipo de relato novelesco en el que se reconozcan los rasgos autobiográficos, pero sin ninguna señal que acredite la común identidad nominal de autor y de personaje, me parece demasiado generales y vagas, y de tenerlas en cuenta habría que considerar cualquier novela con indicios auto- biográficos una autoficción. (p. 237).

Resulta interesante que solo unas líneas más adelante, siguiendo las ideas de Philippe Lejeune sobre el pacto autobiográfico, afirme que, para él, la autoficción permite las mismas opciones de presentar la identidad del autor, narrador y protagonista:

[...] la identidad de autor y narrador puede estar ratificada según dos maneras: una, explícita, es decir, cuando el nombre o el apellido del autor, o ambos, aparecen de manera inequívoca en el texto; y otra, implícita, cuando ausente el signo onomástico, se suple éste mediante diferentes señales textuales que cumplen similar función identificadora. (Lejeune, citado en Alberca, 2007, pp. 237-238).

Entendida de esta manera, Formas de volver a casa puede ser leída como una obra autoficcional en la que la identidad del autor, narrador y personaje, se establece de forma implícita $y$, por tanto, de forma borrosa o imprecisa. En este caso, las señales textuales son, por ejemplo, la coincidencia de edad que tienen personaje, narrador y autor, en el momento del terremoto. Para la fecha en la que este ocurre (3 de marzo de 1985), Alejandro Zambra, nacido un 24 de septiembre de 1975 , cuenta con nueve años, al igual que la voz al interior del relato: "Claudia tenía doce años y yo nueve, por lo que nuestra amistad era imposible» (p. 14). Otro tanto ocurre con el lugar de residencia de los padres: Maipú; el colegio en el que estudiaron la secundaria: Instituto Nacional General José Miguel Carrera; los estudios universitarios: Literatura; y, en fin, la profesión: escritor.

Un elemento interesante de la lectura es la confusión del lector. Esta es una confusiónpropiciada y calculada. ¿Qué finalidad puede orientar la decisión de ofrecer en el texto datos ambiguos o engañosos o, incluso, confusos, al lector? Sin duda, la decisión actúa de forma especular sobre el lector. Hacer que las fronteras, los hechos narrados, se vuelvan inestables, cuestionables, que impidan delimitar los hechos del pasado con precisión, apela a la responsabilidad del lector. No se cuestiona la responsabilidad directa del lector en lo relativo a los hechos narrados, sino la responsabilidad que como lector le corresponde en relación con los hechos del pasado. La anonimia del narrador facilita esta transición entre derechos personales y colectivos, entre la exigencia de la responsabilidad y la absolución de la irresponsabilidad.

Por otra parte, la primera persona trae a la conciencia del lector la urgencia de la inmediatez. Lo 
narrado no se conoce a través de una tercera persona que le autoriza a quien lee a interponer cierta distancia. La anonimia, por su parte, permite, a quien lea, una identificación parcial con las tribulaciones del protagonista.

Por último, la forma en la que el yo se desfigura en datos que no contradicen lo que se sabe del autor, pero no son comprobables, estimula la imaginación de los potenciales lectores en la dirección en la que se apela a una experiencia de lo narrado. Todo esto sería significativo en el plano de las confesiones personales. Que un autor decida dar forma narrativa a su autobiografía, que introduzca elementos autoficcionales en un discurso confesional, no es incompatible con lo dicho anteriormente, pero su esfera de influencia es limitada, es una influencia cuyas fronteras naturales son la de la circunferencia de lo personal.

Cuando en el tiempo de lo narrado se incluyen un terremoto y una dictadura, entonces el punto de vista que se exige no es el de la simple noción de fidelidad personal a los hechos ocurridos. Hay algo más. Hay responsabilidades y sentidos de la lectura que dejan de ser individuales y son, simultáneamente, colectivos. Y este hecho, que el campo de expresión de lo autoficcional sea el de la experiencia colectiva, es lo que convierte a esta novela en una obra que explora nuevas formas de expresión de lo individual. Lo autoficcional, en términos generales, ha hallado tradicionalmente un suelo más fértil en el campo de la expresión de lo íntimo y de las emociones.

Entre dos terremotos y una dictadura

La estructura particular que tiene Formas de volver a casa, es decir, la organización una novela en la que confluyen los procedimientos autoficcionales por medio de un diario, la ficcionalización de la vida y recuerdos de Zambra en un relato sobre el que, metafictivamente, el narrador-escritor reflexiona al interior de la obra, y la exposición explícita, por medio de anécdotas que se replican con variaciones en las distintas partes de la novela; hacen todavía más evidente la intención de Zambra de mostrar la forma en que pueden modificarse los recuerdos. Intensifican una experiencia en la que se induce al lector a que se cuestione sobre cómo se erige la vivienda de la memoria y cómo esta se relaciona con el pasado, cómo se entreteje lo recordado con lo que efectivamente ocurrió.

Llama la atención que, en un momento dado, dentro de lo que se considera uno de los capítulos escritos como diario, el narrador se vea cuestionado por el tema mismo sobre el que está escribiendo y sobre su aparición o intervención en la ficción. Interpelado por la hermana, el personaje afirma:

No quiero responderle, ella se da cuenta y vuelve a preguntar. Le digo que de Maipú, del terremoto de 1985, de la infancia [...] Sé muy bien lo que va a preguntarme.

¿Salgo yo en tu libro?, dice al fin.

No.

¿Por qué?

Lo he pensado. Claro que lo he pensado. Lo he pensado mucho. Mi respuesta es muy honesta:

Para protegerte, le digo. Ella me mira escéptica, dolida. Me mira con cara de niña.

Es mejor no ser personaje de nadie, digo. Es mejor no salir en ningún libro.

¿Y tú sales en el libro?

Sí. Más o menos. Pero el libro es mío. No podría no salir. Aunque me atribuyera otros rasgos y una vida muy distinta de la mía, igual estaría yo en el libro. Yo ya tomé la decisión de no protegerme.

¿Y salen nuestros padres?

Sí. Hay personajes parecidos a nuestros padres.

¿Y por qué no proteges, también, a nuestros padres?

Para esa pregunta no tengo ninguna respuesta. Supongo que les toca, simple- 
mente, comparecer. Recibir menos de lo que dieron, asistir a un baile de máscaras sin entender muy bien por qué están ahí. Nada de esto soy capaz de decírselo a mi hermana.

No lo sé, es ficción le digo. (Zambra, 2011, pp. 81- 82).

Este fragmento permite analizar dos temas interesantes en la obra. El primero tiene que ver, directamente, con la ficcionalización de la vida del narrador-escritor; es decir, con la del propio Zambra. El narrador deja claro que, detrás de la aparición de él o de su familia al interior de la novela que escribe, hay intenciones bastante evidentes y que es consciente de las implicaciones que trae consigo incluir en un relato de ficción fragmentos de su propia vida, de sus recuerdos y de su relación con otros. Presentarse como personaje es exponerse y librarse de cualquier tipo de protección. Es abandonarse a los juicios que, sobre sus acciones, puedan hacer los demás. Mientras que incluir a sus padres como personajes puede entenderse como un ajuste de cuentas con respecto a los eventos ocurridos durante el tiempo que se relata. Es, además, llevar a aquellos ante el juicio y la mirada objetiva del lector.

En ese mismo sentido, la preocupación que sobre estos asuntos el autor hace explícita para el lector, predispone y dirige la lectura hacia cuestiones muy concretas. El narrador desea que el lector atienda a lo que implica la acción de exponerse al exhibir a sus familiares en una ficción, desea que comparezcan ante el juicio del lector, que respondan, al menos en la ficción, y que se les haga responsables por sus acciones $\mathrm{u}$ omisiones. También busca que se destaque la importancia de que lo que narra, aunque sean recuerdos de infancia, aunque la historia parta los recuerdos de un niño, poseen el mismo valor e importancia que los que, de esa época, pudieran tener los adultos.

El segundo tema del fragmento sobre el que resulta relevante detenerse, es el que relaciona la narración directamente con el terremoto de 1985. La mención parecería ser la de un elemento más sobre el que el narrador pretende escribir; sin embargo, al resumir su novela como una novela en la que tratará de un terremoto y de la infancia, implícitamente, le dice al lector que la obra también discurre sobre una catástrofe, y sobre cómo esta se puede enfrentar siendo niño.

Permite, asimismo, que se considere la posibilidad de que ese terremoto se entienda, también, como una metáfora de una situación particular que desestabiliza la vida de una familia y de la sociedad en la que vive, de
Maipú, en este caso. En una escala de gradaciones de lo posible, un terremoto es inevitable, es impredecible y hay en él, en los terremotos, un abrumador sobrepasamiento de lo humano. Un terremoto es lo incontrolable de la naturaleza. Los efectos y consecuencias de este en la naturaleza humana, en la individual y en la colectiva, no son asimilables ni racionalizables, están más allá de todo control e, incluso, están precariamente incluidos en la prevención. Nunca se ve venirun terremoto, pero pueden tomarse medidas preventivas y paliativas frente a ellos, que hagan menos devastadores los daños. La experiencia humana ante el terremoto no puede ser sino, en buena medida, pasiva. ¿Es comparable esa experiencia con aquella que surge de la vida bajo la dictadura?

Llama la atención que la obra se halle enmarcada entre dos terremotos. La anécdota con la que se abre Formas de volver a casa es el relato de lo ocurrido la madrugada del terremoto de 1985 , sobre el que, como se ha expuesto, el narrador explica que trata su novela; mientras que se cierra con la descripción de cómo este escritor se enfrenta a otro terremoto, el que ocurrió en Santiago de Chile el 27 de febrero de 2010 y que dejó más de dos millones de damnificados. Sin embargo, ninguno de los dos es descrito con especial atención. En el primer caso, el personaje, más que centrarse 
en los efectos que se podrían relacionar con evento de esta naturaleza, enfoca su relato en el efecto que le causó conocer a la sobrina de uno de sus vecinos. En el segundo texto, es decir, en el que corresponde al diario del narrador, la aparente destrucción que produce el segundo terremoto se reduce a unos platos rotos, dos ventanales y algunos libros tirados en el suelo. En este punto, no resulta extraño que el lector se pregunte, entonces, ¿a qué terremoto se refieren cuando se insiste en que la obra trata sobre un terremoto?

Quizá, la clave que se oculta tras la metáfora del terremoto se encuentra en la aparición o desaparición de las personas, e indica que hay muchas maneras de desestabilizar un mundo. Pero se contraponen, mediante esta forma de narración, los datos materiales y empíricos: la muerte, la devastación, la destrucción de la obra humana, la dificultad o imposibilidad de la comunicación, la evaluación de los daños, la reconstrucción; todo esto no es sino el paisaje completo, la gran panorámica que reproduce y amplifica la magnitud de lo ocurrido. Hay otra forma de percibir lo que ha sucedido, y que consiste en enumerar, desde el punto de vista del individuo, del yo, los cambios más cercanos al sujeto, las minúsculas o grandes alteraciones, la insuficiencia del punto de vista único, personal. El pai- saje ha cambiado. Los cambios deben entenderse, justificarse en un mundo irrevocablemente alterado.

En el edificio de lo humano, el terremoto puede ser una dictadura que destruye las instituciones democráticas y que las sustituye por la camisa de fuerza de la autoridad. A todo ello, le sigue la reconstrucción a partir del momento en que se recupere la normalidad democrática, la vida que se llevaba antes. Pero en el caso de quienes solo vivieron el final de la dictadura siendo niños, la novela funciona como una representación de ese tejido en el que las figuras de lo conservado y de lo dibujado de nuevo pretenden disimular el deterioro que trajo consigo la violencia, las desgarraduras, los cortes, o lo desaparecido, todo aquello que se enfrenta después de un terremoto, el proceso de destrucción y el de reconstrucción. De igual modo, la vida antes y después del prolongado terremoto de la dictadura. El tejido mostrará los zurcidos y los remiendos, sin duda, pero será una manifestación de la voluntad humana de recomponer, de volver a dar utilidad a lo que se destruyó, de reparar.

Ni el terremoto ni la dictadura son objeto de descripción directa. Son acontecimientos que se conocen acaso mejor en sus ondas expansivas que en el relato de los hechos mismos. Son objeto de atención en el microcosmos del hogar, en las alteraciones minúsculas, en las roturas, en los silencios, en los cambios. Son consecuencias de ambos acontecimientos que, tal vez desde el presente en el que se escribe, no se identifican de forma correcta con sus causas. Es la memoria la que, al reconstruir, relaciona causas y consecuencias, la que permite un acceso a la verdad que estaba vedado al suceso al vivir los acontecimientos en tiempo presente.

Pero el terremoto, al mismo tiempo, puede ser una representación de lo desestabilizadoras o devastadoras que pueden llegar a ser las relaciones de pareja. Las rupturas de las relaciones también dejan desapariciones, vacíos. Son sismos que desequilibran la vida y la historia que se ha construido durante su existencia.

En la novela, en los capítulos 1 y 3 , el personaje, siendo niño, conoce a Claudia, la supuesta sobrina de su vecino Raúl, y con la que veinte años más tarde se reencontrará y mantendrá una relación amorosa, época en la que, al igual que el autor del diario y que Alejandro Zambra, el autor de Formas de volver a casa, se dedica a la escritura. Con Claudia, hasta el momento en el que ella decida abandonarlo, rememorará su infancia y los recuerdos que los unen; $y$, analizará la dificultad de entender el comportamiento de sus padres. 
Ella será determinante para la estabilidad de su memoria y para su relación con el pasado.

Del mismo modo, el narrador del diario, a lo largo de dos capítulos, se enfrenta a un proceso en el que intenta reconciliarse con su exesposa, a quien llama «Eme». Todo el tiempo aspira a restaurar un matrimonio fallido, cuyo único problema, según afirma el personaje, fue «que no mentíamos. Fracasamos por el deseo de ser honestos siempre» (p. 54). Eme tiene una función determinante en la vida de este escritor, toda vez que es en ella en quien se basa para escribir su novela.

La obra, en definitiva, es producto de los recuerdos de infancia, tanto de este narrador como de su exesposa. Pero en Eme, además, confluyen otros dos elementos que permiten leer Formas de volver a casa como obra autoficcional. El primero tiene que ver con la profesión que ella ejerce (diseñadora), $y$ que coincide con la que desempeñaba la exesposa de Alejandro Zambra. El segundo tiene que ver con una preocupación que se hace presente en casi toda la obra narrativa del escritor chileno: es la inquietud por lo que se puede o debe contar, y el derecho que se tiene de hacerlo. En la novela que escribe el personaje, este se debate entre si es correcto o no contar la historia de Claudia:
Entonces recordé intensamente a Claudia, pero no quería o no me atrevía a contar su historia. No era mía. Sabía poco, pero al menos sabía eso: que nadie habla por los demás. Que aunque queramos contar historias ajenas terminamos siempre contando la historia propia. (p. 105).

Un poco más adelante el lector se entera de algo que, hasta ese momento, solo se había insinuado: que la historia y recuerdos de Claudia que han dado forma a la novela que escribe, son, en realidad, la vida y los recuerdos de Eme.

De pronto, inesperadamente, Eme comenzó a hablar sobre la novela. Le había gustado, pero durante su lectura no había podido evitar una sensación ambigua, una vacilación. Has contado mi historia, me dijo, y debería agradecerlo, pero pienso que no, que preferiría que esa historia no la contara nadie. Le expliqué que esa no era exactamente su vida, que solamente había tomado algunas imágenes, algunos recuerdos que habíamos compartido. No des excusas, dijo: dejaste algunos billetes en la bodega pero igual robaste el banco, me dijo. (p. 159).
Después del encuentro en el que Eme le reprocha esto al personaje, ellos se separan definitivamente. La separación, parece insinuar Zambra, es una pequeña desaparición, es una muerte, tiene un efecto tan devastador como el de un terremoto. No en vano una de las últimas cosas que hace el personaje en la obra es recorrer las calles que separan su casa de la de Eme, durante la madrugada del terremoto del 2010, para comprobar que ella está bien.

\section{La villa de los nombres reales}

Como se ha señalado, en las obras autoficcionales, la identificación onomástica es un asunto de gran relevancia. Téngase en cuenta que «el nombre constituye dentro de cualquier discurso una marca que no solo identifica, sino que individualiza o agrupa según sea el caso [...] Nombrar es, indirectamente, hacer existir a las personas o las cosas» (Saavedra, 2014, p. 235). En ese sentido, la anonimia de los personajes de Formas de volver a casa, tanto del autor del diario como del personaje de la novela que este escribe, refleja un interés oscilante entre el deseo de mostrar y de ocultar. Pero también puede tener relación con aprovechar todas las posibilidades que ella permite. Un interés bien reflejado en la cita con la que se abren estas páginas. «Leer es cubrirse la cara. Y escribir es mostrarla» (Zambra, 2011, p. 66). Se eje- 
cutan ambas operaciones sobre el mismo texto, la escritura y la lectura; el autor es lector de su misma obra. Entonces la ocultación y el desvelamiento se alternan en el proceso de creación. La anonimia y la revelación del yo ocurren simultáneamente y, en cierta forma, se anulan entre sí, para abrir paso a una nueva forma de conciencia que suma lo anterior en un espacio nuevo que es el que únicamente puede conocerse en las páginas de esta obra. Esa nueva conciencia es la que puede conocer el lector, como si atendiera a aspectos diferenciados de la realidad.

Al explicar los procedimientos autoficcionales en obras en las que no hay una identificación onomástica que vincule al autor, narrador y personaje, Alberca (2007) toma como ejemplo paradigmático de este tipo de autoficciones a Todas las almas, de Javier Marías, y sobre esta obra advierte que:

Es sabido que el anonimato de la voz narrativa supone una estrategia de fingimiento, es de hecho el primer escalón de la invención narrativa, pues el autor se borra o desaparece tras el «yo» anónimo, se hace otro [...] Todo está dispuesto para provocar la identificación entre autor y protagonista $\mathrm{y}$, al mismo tiempo, para que no pueda llegar a producirse $y$, si se produce, lo sea de manera insegura e incompleta. Marías maneja aquí de manera intencionada el esquema autoficticio, se permite jugar con él y también transgredirlo en una maniobra que afirma y niega los principios del género. Ésta es para mí la mayor virtud del relato en tanto que maquinaria narrativa: haber extendido la indeterminación del texto no sólo al juego de planos, sino haberla intensificado en torno al equívoco del nombre. Tan acertado me parece el artificio trasgresor que, dentro de su excepcionalidad, me inclino a considerarlo modélico (pp. 246-247).

Alberca señala que Marías juega de manera intencional con la anonimia y con el «esquema autoficticio», y otro tanto se podría afirmar de lo que hace Alejandro Zambra en la novela que es materia de análisis en estas páginas. Un indicio de eso es que, nada más empezar el segundo capítulo, el párrafo con el que se abre el diario, expone su conciencia sobre la importancia de los nombres y sobre la función de estos dentro de una obra de ficción.

Avanzo de a poco en la novela. Me la paso el tiempo pensando en Claudia como si existiera, como si hubie- ra existido. Al comienzo dudaba incluso de su nombre. Pero es el nombre del noventa por ciento de las mujeres de mi generación. Es justo que se llame así. No me cansa el sonido, tampoco. Claudia.

Me gusta mucho que mis personajes no tengan apellidos. Es un alivio. (Zambra, 2011, p. 53).

Este es uno de los motivos por los que vale la pena prestar atención a la forma en la que son mencionados todos los personajes, y a los momentos en los que se emplean nombres propios. A los padres y a la hermana, por ejemplo, elude llamarlos con un nombre identificable; es decir, los expone en la ficción, pero también juega a ocultarlos: «Tengo que irme, hermana. No la llamo por su nombre. Le digo hermana» (p. 82). Sin embargo, no ocurre lo mismo con los amigos y conocidos del narrador, por ejemplo, con la visita que le hace el poeta Rodrigo Olavarría (p. 70) o la llamada de Alejandra Costamagna (p. 153). Este detalle se vincula con el tipo de trasgresión a la que se refiere Alberca. Zambra conoce y manipula a la perfección, la importancia de esos signos de identificación, y juega con ellos para que promuevan en el lector una duda razonable sobre lo biográfico y lo ficcional dentro del relato. 
Pero el ejemplo más esclarecedor sobre la relevancia de los nombres en Formas de volver a casa, se esconde tras el único fragmento en el que se usa un recurso onomástico para llamar al personaje de la novela que escribe el narrador y que, a su vez, se desprende de una anécdota que ha contado sobre su infancia. Durante esta, el personaje vive en un pasaje o calle que responde al nombre de Aladino, entre Ramayana y Odín, y paralela a Lemuria. En la misma época, durante el tiempo que le permitirá conocer la casa en la que vive Claudia, comenta que:

Buena parte de las calles de Maipú tenían, tienen esos nombres absurdos: Mis primos, por ejemplo, vivían en el pasaje Primera Sinfonía, contiguo al Segunda y al Tercera Sinfonía, perpendiculares a la calle El Concierto, y cercanos a los pasajes Opus Uno, Opus Dos, Opus tres, etcétera [...] Se ve que a fines de los setenta había gente que se divertía mucho eligiendo nombres de los pasajes donde luego viviríamos las nuevas familias, las familias sin historia, dispuestas o tal vez resignadas a habitar ese mundo de fantasía» ( $p$. 28).

Claudia, entre tanto, vivía en una villa de solo dos calles (Lucila Godoy Alcayaga y Neftalí
Reyes Basoalto) y que, según su propia descripción, correspondía a la villa de los nombres reales. La niña es enfática con esta descripción.

Vivo en la villa de los nombres reales, dijo de nuevo, como si necesitara recomenzar la frase para continuarla: Lucila Godoy Alcayaga es el verdadero nombre de Gabriela Mistral, explicó, y Neftalí Reyes Basoalto el nombre real de Pablo Neruda. Sobrevino un silencio que rompí diciéndole lo primero que se me ocurrió: vivir aquí debe ser mucho mejor que vivir en el pasaje Aladino.

Hay, hasta aquí, un juego entre el nombre de verdad y el nombre ficticio. Los nombres más o menos fantásticos del barrio de Maipú son un buen ejemplo. Son «nombres absurdos» que, ciertamente, figuran en el callejero y pueden identificarse en el extremo norte de Maipú, en Santiago de Chile. En el mapa en el que se representan los valores simbólicos, estos nombres existen para proporcionar diversión a quienes los eligieron. Sin duda, la pasión melómana era adecuada para proporcionar un lugar en el que se asentaran «las nuevas familias, las familias sin historia», pero se supone que a las nuevas familias no se les consultó, no fueron parte en el proceso en el que se hizo oficial la toponimia menor del barrio. Se contraponen a estos nombres, los nombres de la «villa de los nombres reales», que, por su parte, participan de su forma propia de irrealidad, los nombres reales son los nombres desconocidos de los autores a los que se conoce por su pseudónimo literario, Gabriela Mistral y Pablo Neruda, la realidad de sus nombres queda oculta para la mayoría de sus lectores. Pocas personas saben que Lucía Godoy Alcayaga era el nombre y apellidos de Gabriela Mistral, y pocas personas saben que Neftalí Reyes Basoalto era el nombre y apellidos de Pablo Neruda. En este caso, se invierte la polaridad. De forma que, la conclusión es evidente: los nombres «absurdos» no se califican por su realidad o irrealidad, sino por su falta de arraigo en la historia; mientras que los nombres reales carecen de curso legal si se contrastan con su irrealidad, con los pseudónimos por los que fueron sustituidos $\mathrm{y}$, por tanto, tienen un ficticio arraigo histórico.

El mapa de la cartografía urbana se levanta sobre decisiones que se improvisan ante lo nuevo, ante «las nuevas familias, las familias sin historia» y sobre las decisiones que desfiguran la historia, que muestran el pasado desconocido que se ocultaba, los nombres tras los pseudónimos. La opción no es envidiable y, como hace el autor, solo irónicamente puede explicarse: 
«vivir aquí debe ser mucho mejor que vivir en el pasaje Aladino». Las que, por contraste, debieron de ser familias arraigadas en la historia muestran su orgullo de clase o su estirpe aristocrática mediante la prueba de la autenticidad del nombre. Hay una verdad histórica que tiene un crédito superior al de la verdad divulgada, porque es más auténtico, es decir, es más verdad, el nombre que el pseudónimo. Ante la autenticidad del nombre restaurado, el pseudónimo es la prueba del engaño histórico.

Quienes viven en el pasaje Aladino saben que viven en el mundo de la ficción, en el exterior de lo inauténtico, que están fuera del círculo mágico del derecho a la autenticidad. Frente a esta revelación, solo cabe el silencio, la sorpresa, la admiración no menos absurda que los nombres musicales del otro barrio. «Sobrevino un silencio que rompí diciéndole lo primero que se me ocurrió»». Hay un mundo «mucho mejor», el mundo de lo auténtico, de lo privativo de las familias con arraigo, de las familias antiguas, las familias con historia. Esos dos mundos son los que se encuentran y reconocen en las páginas de Formas de volver a casa.

Lo anterior se emparenta con un elemento determinante en el juego de onomástica que propone la obra: veinte años después del recorrido que el personaje y Claudia hacen por las calles de Maipú, el personaje vuelve a buscar a su amiga de infancia $\mathrm{y}$, al llegar a la casa y conversar con Ximena, la hermana de Claudia, esta, por primera y única vez en todo el relato, emplea un signo onomástico para referirse al personaje:

La mujer iba a irse cuando le dije, casi gritando: Claudia.

Quién eres tú, respondió.

Se lo dije. Le dije que nos habíamos conocido en Maipú. Que habíamos sido amigos.

Ella me miró largamente. Yo me dejé mirar. Es extrañísima esa sensación. La de esperar ser reconocido. Al final me dijo: ya sé quién eres. Yo no soy Claudia. Soy Ximena, la hermana de Claudia. Y tú eres el niño que me siguió esa tarde, Aladino. Así te decía Claudia, nos reíamos mucho cuando se acordaba de ti, Aladino (pp. 90-91).

Alejandro Zambra y, su vez, el narrador, eligen usar como nombre para el personaje un signo onomástico ligado con una clara carga de ficción y de, como se ha señalado antes, conciencia sobre el mundo fantástico en el que se habita. El personaje no solo vive en él, sino que es, de alguna manera, eso: una ficción. Él y todo su universo está incluido en «Odín», un dios nórdico relacionado con la guerra, la muerte y, entre otros, con la sabiduría y la poesía; «Ramayana», una epopeya india en la que el protagonista intenta rescatar y salvar a su amada; y Lemuria, un supuesto continente desaparecido entre África y la India que ha servido a escritores como H. P. Lovercraft o Thomas Pynchon para ubicar sus relatos. Llamándose «Aladino» no puede haber en él o en su vida ninguna certeza sobre lo que corresponde a la realidad. Pero, a la vez, el improvisado bautizo equipara al narrador a esos nombres de la verdad que ocultaba el pseudónimo. El protagonista recibe su pseudónimo y alcanza el reconocimiento de ese barrio en el que se conocen ambos nombres, el real y el pseudónimo. También él puede decir su nombre y puede ser conocido mediante un pseudónimo. Pero se intensifica la duda sobre qué de lo que se narra hace parte de la ficción, y qué datos hacen parte de la vida de Alejandro Zambra.

Finalmente, es importante analizar un último elemento vinculado al juego de nombres en Formas de volver a casa. Se trata del momento en el que Claudia, siendo adulta, le confiesa al personaje que el vecino al que, siendo niño conoció como Raúl y que creía que era su tío, en realidad se llamaba Roberto y era su padre. Claudia le cuenta que, durante la dictadura, su padre había sido un militante clandestino de un partido político proscrito y que, en un 
momento dado, es perseguido y amenazado, razón por la que deciden pedirle a su cuñado que huya a Argentina y le preste su identidad: su nombre. Según el relato, hasta comienzos de 1988 y hasta que así lo decide el partido, la mentira se mantiene. La mujer lo relata así:

La situación era absurda. Hacía una semana Roberto había salido a Buenos Aires con la identidad de Raúl y regresaba convertido en Roberto. Se había recortado un poco el pelo y las patillas y vestía sobriamente, con blue jeans y una camisa blanca. Sonreía mucho y en algún minuto Claudia pensó que parecía un hombre nuevo.

No era necesario que fingiera tanto pero su madre insistía: del mismo modo que antes la miraba con reprobación cuando le decía papá, ahora la instaba, de forma casi ridícula, a que le dijera papá. En el avión venía gente que de verdad había estado exiliada. Claudia recuerda haber sentido una cierta amargura al verlos abrazar a sus familias, llorar en esos abrazos largos, legítimos. Por un momento pensó, pero se arrepintió enseguida de ese pensamiento, que los demás también fingían. Que lo que recuperaban no era a la persona sino los nombres. Deshacían, por fin, esa distancia entre los cuerpos y los nombres. Pero no. Había alrededor emociones verdaderas. Y de vuelta a casa pensó que su emoción era también verdadera (pp. 118-119).

Los nombres ocultaban el drama o lo hacían patente. Las calles de los barrios recibían nombres absurdos o recibían nombres que pretendían exhibir su arraigo histórico. Las personas tenían que cambiar de nombre durante la dictadura, pero el cambio de nombre acarreaba también un cambio de personalidad y un cambio en la estructura familiar. El baile de disfraces se convierte en un psicodrama colectivo, y las consecuencias de la dificultad de presentarse bajo el nombre propio se pagan en forma de desconfianza colectiva. Si las estructuras de parentesco, las de la familia nuclear, se ven alteradas por un cambio de nombre, si los nombres no los llevan quienes tienen legitimidad para llevarlos, entonces la desconfianza en los tiempos de la dictadura es generalizada: nadie puede tener la certeza de que la persona a quien ha llamado tío durante toda su vida no sea, en realidad, su padre. La lectura política es desalentadora, pero eso lleva el análisis de la autoficción a otro terreno, al terreno en el que las responsabilidades son algo más que la incertidumbre respecto de la continuidad de la experiencia y su revalidación en la experiencia de los demás, la diferencia y discontinuidad entre lo que verdaderamente ocurrió y lo que acaso pudo haber ocurrido.

\section{Referencias}

Alberca, M. (2007). El pacto ambiguo. De la novela autobiográfica a la autoficción. Madrid: Biblioteca Nueva.

Casas, A. (comp.) (2012a). La autoficción. Reflexiones teóricas. Madrid: Arco Libros. 
Casas, A. (2012B). El simulacro del yo: la autoficción en la narrativa actual. En A. Casas (comp.), La autoficción. Reflexiones teóricas. Madrid: Arco Libros.

Doubrovsky, S. (1988). Autobiographiques. París: PUF.

Doubrovsky, S. (1977), Fils. París: Galilée.

Saavedra Galindo, A. (2014). Pragmática y onomástica. En A. Vital, A. Saavedra Galindo y C. Cañedo (Comps.) (ed.), Manual de Pragmática de la Comunicación Literaria (pp. 235-252). México: Universidad Nacional Autónoma de México-UNAM.

Zambra, A. (2011). Formas de volver a casa. Barcelona: Anagrama. 